\title{
The Influence of Ethanol on Pyruvate Kinases Activity in Vivo, in Vitro, in Silico
}

\author{
Lelevich Sergey Vladimirovich ${ }^{1}$, Khrustalev Vladislav Victorovich ${ }^{2, *}$, Barkovsky Eugene Victorovich ${ }^{2}$, \\ Shedogubova Tatyana Aleksandrovna ${ }^{3}$
}

\author{
${ }^{1}$ Department of Clinical Laboratory Diagnostics, Allergology and Immunology, Grodno State Medical University, Grodno, Belarus \\ ${ }^{2}$ Department of General Chemistry, Belarusian State Medical University, Minsk, Belarus \\ ${ }^{3}$ Multiple-discipline Diagnostic Laboratory, Institute of Physiology of the National Academy of Sciences of Belarus, Minsk, Belarus \\ *Corresponding author: vvkhrustalev@mail.ru
}

Received December 28, 2012; Revised January 23, 2013; Accepted February 15, 2013

\begin{abstract}
The influence of ethanol on enzymatic activities of muscle and liver pyruvate kinases has been studied in rats in series of in vivo and in vitro experiments accompanied by in silico study. Activity of muscle pyruvate kinase significantly decreased in experiments on acute alcohol intoxication $(5.0 \mathrm{~g} / \mathrm{kg}$ of body weight), during chronic alcohol consumption $(3.5 \mathrm{~g} / \mathrm{kg}$ of body weight 2 times a day for 14 and 28 days) and during the abstinence after the period of alcohol consumption $(5.0 \mathrm{~g} / \mathrm{kg}$ of body weight 2 times a day for 5 days). Activity of liver pyruvate kinase was not decreased in rats after the period of alcohol consumption $(5.0 \mathrm{~g} / \mathrm{kg}$ of body weight 2 times a day for 5 days) and during chronic alcohol consumption $(3.5 \mathrm{~g} / \mathrm{kg}$ of body weight 2 times a day for 28 days). It even became significantly higher during the chronic alcohol consumption $(3.5 \mathrm{~g} / \mathrm{kg}$ of body weight 2 times a day) lasting for 14 days. Inhibitory effect of alcohol bolus on activities of both pyruvate kinases should be linked with certain indirect mechanisms, since direct inhibitory effect was seen in vitro only after the addition of $500 \mathrm{mM}$ ethanol to the rat muscle and liver supernatants. Since lactate dehydrogenase is used in a coupled assay for pyruvate kinase activity estimation we approved that $500 \mathrm{mM}$ ethanol did not inhibit lactate dehydrogenase activity in human plasma. Direct inhibition of pyruvate kinases activities should be due to the ability of ethanol to bind amino acid residues from the known allosteric site for alanine binding on muscle and liver pyruvate kinases shown by us with the help of molecular docking. Indirect activation of liver pyruvate kinase can be explained by the increase of glucose blood levels in rats during alcohol consumption promoting dephosphorylation of the enzyme as well as expression of the gene coding for it, and the decrease of alanine concentration in liver.
\end{abstract}

Keywords: Ethanol, Muscle pyruvate kinase, Liver pyruvate kinase, Acute alcohol intoxication, Chronic ethanol intoxication, Ligand docking

\section{Introduction}

Ethanol is a small molecule which may interact with different human proteins and not just with alcohol dehydrogenases. It was shown that ethanol is an allosteric modulator of several human brain receptors, such as gamma-aminobutyric acid (GABAA) [23], N-methyl-Daspartate (NMDA) [27] and glycine receptors [31]. Moreover, ethanol was shown to promote transcription of dopamine $\beta$-hydroxylase (DBH) mRNA [13]. Later high bolus dose of ethanol $(6 \mathrm{~g}$ per $\mathrm{kg}$ of body weight) was shown to change the expression of 646 genes in rat liver cells at 3 hours after admission [22]. In general, ethanol may participate in hydrophobic interactions with amino acid residues due to the presence of $\mathrm{CH} 3-\mathrm{CH} 2$ - group and in polar interactions due to the presence of $-\mathrm{OH}$ group. The presence of $-\mathrm{OH}$ group also makes ethanol able to participate in hydrogen bond formation.

Pyruvate kinase is one of the three key enzymes in glycolysis [29]. It catalyzes the transfer of a phosphate group from phosphoenolpyruvate (PEP) to ADP. There are two products of this reaction: one molecule of pyruvate and one molecule of ATP. This reaction is the final one in aerobic glycolysis. In anaerobic glycolysis pyruvate is reduced to lactate by lactate dehydrogenase. There are two genes coding for pyruvate kinase in genomes of vertebrates. One of those genes is coding for pyruvate kinase expressed in liver and red blood cells, the second one is coding for pyruvate kinase expressed in skeletal muscles. Even though those two enzymes share a high degree of similarity in primary and, especially, in secondary and tertiary structures, enzymatic activity of the muscle pyruvate kinase is approximately 10 times higher than that of the liver pyruvate kinase. It is known that liver pyruvate kinase is a subject of indirect activity regulation by insulin [5,26], glucagon [2], epinephrine and even glucose blood levels [6], while muscle pyruvate kinase is not.

The main purpose of the present study was to find out how alcohol consumption influences activities of muscle and liver pyruvate kinases. Three types of experiments (in vivo, in vitro and in silico) have been performed to clarify these issues. Acute and chronic alcohol consumption, as well as abstinence syndrome have been modeled in rats. Acute alcohol intoxication has been modeled for low $(1.0 \mathrm{~g}$ per $\mathrm{kg}$ of body weight), average $(2.5 \mathrm{~g}$ per $\mathrm{kg}$ of body 
weight) and high doses (5.0g per $\mathrm{kg}$ of body weight) of ethanol [32]. Chronic consumption and withdrawal effect have been modeled only for doses of ethanol usually classified as high ones [32]. Docking of ethanol to human and rat muscle and liver pyruvate kinases has been performed with the help of Docking Server [1] (http://www.dockingserver.com): putative ethanol binding sites have been described.

In general, glycolysis is inhibited in the period of alcohol consumption [21]. The cause of this inhibition is thought to be indirect [5,21]. The pathway of ethanol metabolism is as follows: ethanol to acetaldehyde; acetaldehyde to acetic acid; acetic acid to acetyl-CoA. Acetyl-CoA entering citric acid cycle is synthesized mostly from ethanol during the period of alcohol consumption and not from glucose [20,21]. Many enzymes including those involved in glycolysis can be altered by acetaldehyde, which is a toxigenic metabolite of ethanol [21]. In this study we came to the conclusion that ethanol itself may bind muscle and liver pyruvate kinases, while the direct inhibitory effect is characteristic to high concentrations of ethanol only, which are above any pharmacologically relevant concentration. Moreover, ethanol may indirectly increase (and not decrease) activity of liver pyruvate kinase through some of the pathways linked with the increase of glucose blood level and the decrease of alanine concentration in liver cells $[3,10,19,25]$.

\section{Materials and Methods}

\subsection{In Vivo Experiments}

In the experiment on the modeling of acute alcohol intoxication twenty nine rats (males, $180-220 \mathrm{~g}$ ) were used. All the rats have not been fed for 11 hours. Then seven rats from the control group received $1 \mathrm{ml}$ of $0.9 \%$ $\mathrm{NaCl}$ intragastrally; seven rats received $25 \%$ ethanol in water solution in dosage of $1.0 \mathrm{~g}$ per $\mathrm{kg}$ of body weight; seven rats received $25 \%$ ethanol in dosage of $2.5 \mathrm{~g}$ per $\mathrm{kg}$ of body weight; eight rats received $25 \%$ ethanol in dosage of $5.0 \mathrm{~g}$ per $\mathrm{kg}$ of body weight. After 1 hour rats from control group and those from three experimental groups have been decapitated. Here and in other experiments adequate measures were taken to minimize pain and discomfort of rats. Experiments have been carried out in accordance with the European Communities Council Directive of 24 November 1986 (86/609/EEC).

In the experiment on the modeling of chronic alcohol intoxication twenty five rats (males, $180-220 \mathrm{~g}$ ) were used. Six rats from the first experimental group received $25 \%$ ethanol in water solution twice a day in dosage of $3.5 \mathrm{~g}$ per $\mathrm{kg}$ of body weight intragastrally during 14 days; seven rats from the second experimental group control group received $25 \%$ ethanol twice a day in dosage of $3.5 \mathrm{~g}$ per $\mathrm{kg}$ of body weight intragastrally during 28 days; twelve rats from the control group received equivolume amount of $0.9 \% \mathrm{NaCl}$ during 28 days. Rats were decapitated after 1 hour since the last alcohol intake.

In the experiment on the modeling of abstinence syndrome forty rats (males, $180-220 \mathrm{~g}$ ) were used. Abstinence syndrome has been modeled according to the methodology proposed by Majchrowich [7] in our own modification. Twenty four rats from experimental groups received $25 \%$ ethanol in water solution twice a day in dosage of $5.0 \mathrm{~g}$ per $\mathrm{kg}$ of body weight intragastrally during 5 days; eight rats from control group received equivolume amount of $0.9 \% \mathrm{NaCl}$. Six rats were decapitated after 3 hours, six rats were decapitated after 24 hours, six rats were decapitated after 72 hours and six rats were decapitated after 168 hours since the last alcohol intake.

Liver and muscle tissues have been homogenized in glass homogenizers. Supernatants have been obtained after the centrifugation of homogenates. Enzymatic activity of pyruvate kinase in all the supernatants of liver and muscle tissues has been measured by a standard method with the help of $0.15 \mathrm{mM}$ NADH (SIGMA); $0.5 \mathrm{mM}$ ADP (SIGMA); $1 \mathrm{mM}$ phosphoenolpyruvate (SIGMA); $0.01 \mathrm{mg}$ lactate dehydrogenase (SIGMA); 8 $\mathrm{mM} \mathrm{MgSO} 4 ; 7.5 \mathrm{mM} \mathrm{KCl} ; 70 \mathrm{mM}$ tris- $\mathrm{HCl}$ buffer $\mathrm{pH}=7.6$. The reaction velocity was determined in a lactate dehydrogenase coupled assay system by measuring the decrease in absorbance at $340 \mathrm{~nm}$ on "SOLAR" spectrophotometer resulting from the oxidation of NADH (NADH is used by lactate dehydrogenase to produce lactate from pyruvate). Activity is expressed in nmol of substrate per $\mathrm{mg}$ of tissue per minute ( $\mathrm{nmol} / \mathrm{mg} / \mathrm{min}$ ).

\subsection{In Silico Experiments}

For docking experiments we used PDB file 1ZJH describing 3D structure of human muscle pyruvate kinase and $\mathrm{PDB}$ file $2 \mathrm{VGB}$ describing 3D structure of liver pyruvate kinase. 3D structure of rat muscle pyruvate kinase has been modeled with the help of Swiss Model [17] server (http://swissmodel.expasy.org): 1ZJH file has been used as a template. 3D structure of rat liver pyruvate kinase has also been modeled with the help of Swiss Model server: 2VGB file has been used as a template.

The docking has been performed with the help of Docking Server [1,14]. For all the four proteins areas with the highest probability of binding site existence have been estimated automatically by the server. Docking Server estimated free energy of binding [14], interacting residues and types of possible interactions between those residues and ethanol. 3D structure of the ethanol has been uploaded by us from the PubChem data base.

Equilibrium binding constants have been calculated from the levels of estimated free energies of binding. Equation 1 has been used for that calculation.

$$
\Delta \mathrm{G}=\square \mathrm{RT} \ln \mathrm{K}
$$

In the Equation $1 \Delta \mathrm{G}$ is an estimated free energy of binding (in $\mathrm{kcal} / \mathrm{mol}$ ); $\mathrm{R}$ is a gas constant $\left(1.99 \cdot 10^{-3}\right.$ $\mathrm{kcal} / \mathrm{mol} \cdot \mathrm{K})$; $\mathrm{T}$ is a temperature $(310 \mathrm{~K})$; and $\mathrm{K}$ is the equilibrium binding constant.

We also performed docking of alanine to 3D structures of enzymes mentioned above. Constants of binding for alanine and ethanol have been compared.

Nucleotide sequences of the following genes have been downloaded from the Ensembl data base [12]. Human (Homo sapiens): muscle pyruvate kinase (ENSG00000067225), liver pyruvate kinase (ENSG00000143627); gorilla (Gorilla gorilla): muscle pyruvate kinase (ENSGGOG00000005062), liver pyruvate kinase (ENSGGOG00000001917); rat (Rattus norvegicus): muscle pyruvate kinase (ENSRNOG00000011329), liver pyruvate kinase (ENSRNOG00000020420); mouse (Mus musculus): 
muscle pyruvate kinase (ENSMUSG00000032294), liver pyruvate kinase (ENSMUSG00000041237); lamprey (Petromyzon marinus): liver pyruvate kinase (ENSPMAG00000000202); yeast (Saccharomyces cerevisiae): pyruvate kinase 1 (YAL038W) and pyruvate kinase 2 (YOR347C).

Nucleotide sequence of lancelet (Branchiostoma floridae) pyruvate kinase has been reconstructed by us from two sources: XP_002605273 and XM_002585913.1. Both of those sequences were found in GenBank data base with the help of BLAST analysis using human muscle pyruvate kinase as a query. We substituted first 134 codons of the XM_002585913.1 sequence (they cannot be aligned with other genes coding for pyruvate kinases) with the XP_002605273 sequence (this sequence annotated as partial demonstrates significant similarity with 5 '-ends of genes coding for pyruvate kinases). We also used sequence coding for oyster (Crassostrea gigas) pyruvate kinase from GenBank (CAJ28914.1).

GC-content in third codon positions (3GC) has been counted for all the sequences by VVK Protective Buffer algorithm [15]. The sequence coding for Saccharomyces cerevisiae pyruvate kinase 2 has been excluded from phylogenetic analysis. This has been done because all of the sequences, except the abovementioned one, have 3GC levels higher than $50 \%$. It means that all the genes coding for pyruvate kinases included in the phylogenetic study evolve under the influence of symmetric mutational GCpressure [16]. The presence of sequences evolving under the different mutational pressure directions in the same set may cause significant deviations in the topology of dendrogram [16].

Amino acid sequences have been aligned by PAM method. Evolutionary amino acid distances have been estimated by JTT method (complete deletion) [24]. Dendrogram has been built by UPGMA method [24]. Operations mentioned in this paragraph have been performed with the help of MEGA 5.1 program [28].

According to the Shapiro-Wilk test of normality, there is a normal distribution of variables in all the groups studied. Two-tailed t-test has been used to obtain P-values for the differences between average levels of enzymatic activities in different groups.

\subsection{In Vitro Experiments}

Supernatants of liver and muscle tissues of six healthy rats (males, $180-220 \mathrm{~g}$ ) never received alcohol have been used for the experiment on direct effect of ethanol on activities of muscle and liver pyruvate kinases. Concentrations of ethanol were: $5 \mathrm{mM} ; 50 \mathrm{mM} ; 100 \mathrm{mM}$ and $500 \mathrm{mM}$. Enzymatic activity of pyruvate kinase in all the supernatants of liver and muscle tissues has been measured by a standard method described above.

In that kind of method ethanol may theoretically interact with any substance from tissue homogenate, while this kind of binding should decrease the inhibitory effect of ethanol on pyruvate kinase activity and not increase it. The substrate (phosphoenolpyruvate) is provided for pyruvate kinase only, while its activity is estimated indirectly by the way of the measuring of NADH level decrease. That is why the decrease of NADH oxidation rates may be not just due to pyruvate kinase activity inhibition but due to lactate dehydrogenase activity inhibition too. According to the data from experimental studies lactate dehydrogenase activity is not affected by the $50 \mathrm{mM}$ ethanol [4]. To approve these data and to test whether lactate dehydrogenase activity is inhibited by higher doses of ethanol we performed additional in vitro experiment.

Lactate dehydrogenase activity has been determined in the human control plasma manufactured by the Republican Research and Practical Center of Transfusiology and Medical Biotechnologies (Minsk, Belarus) in the presence of $50 \mathrm{mM}, 100 \mathrm{mM}$ and $500 \mathrm{mM}$ ethanol solutions, as well as in the presence of deionized water of an equal volume. Lyophilized control plasma from 40 healthy donors $20-40$ years old has been reconstituted with $1 \mathrm{ml}$ of deionized water. Lactate dehydrogenase activity has been estimated with the help of an assay manufactured by "Analys-X" company (Minsk, Belarus).

To calculate enzymatic activity (expressed in U/L) we divided the difference of absorbance at $340 \mathrm{~nm}$ measured on "SOLAR" spectrophotometer resulting from the oxidation of NADH during 3 minutes at $37^{\circ} \mathrm{C}$ by three. Then we multiplied that value by the coefficient equal to 21375. The original coefficient from the assay instruction (16031) has been corrected since the final volume of the cuvette has been increased (from 3 to $4 \mathrm{ml}$ ). $98 \%$ ethanol had been diluted in deionized water first and then appropriate solutions have been added to the samples $(1 \mathrm{ml}$ per cuvette). The influence of each concentration of ethanol on lactate dehydrogenase activity has been checked five times.

\section{Results}

\subsection{Acute Alcohol Intoxication}

Results of the experiment on acute alcohol intoxication are represented in Figure 1. Activity of the liver pyruvate kinase in the control group was equal to $64.30 \pm 5.96 \mathrm{nmol} / \mathrm{mg} / \mathrm{min}$. Activity of the liver pyruvate kinase in the group of rats received $1.0 \mathrm{~g}$ per $\mathrm{kg}$ of ethanol $(49.50 \pm 4.09 \mathrm{nmol} / \mathrm{mg} / \mathrm{min})$ was significantly lower $(\mathrm{P}=$ 0.0022 ) than in the control group, as well as than that in the group of rats received $2.5 \mathrm{~g}$ per $\mathrm{kg}$ of ethanol $(57.90 \pm 5.14 \mathrm{nmol} / \mathrm{mg} / \mathrm{min})$. Interestingly, the difference between liver pyruvate kinase activity in the last group (rats received $2.5 \mathrm{~g}$ per $\mathrm{kg}$ of ethanol) and the control group was insignificant $(\mathrm{P}=0.1374)$. Activity of liver pyruvate kinase in the group of rats received the highest dosage of ethanol $(5.0 \mathrm{~g}$ per $\mathrm{kg})$ was significantly lower $(43.70 \pm 5.02 \mathrm{nmol} / \mathrm{mg} / \mathrm{min})$ than in the control group $(\mathrm{P}=$ $0.0002)$ and in the group received $2.5 \mathrm{~g}$ per $\mathrm{kg}$ of ethanol $(\mathrm{P}=0.0020)$, but it was close to that in the group received $1.0 \mathrm{~g}$ per $\mathrm{kg}(\mathrm{P}=0.1032)$. In general, liver pyruvate kinase activity demonstrates nonlinear dependence on the ethanol dosage: it is decreased by low and high doses of ethanol, and it is not decreased by the average dose (see Figure 1 A).

In contrast, muscle pyruvate kinase activity is decreased (relative to the control group) only in rats received the highest dosage of ethanol $(5.0 \mathrm{~g}$ per $\mathrm{kg}$ ) (see Figure $1 \mathrm{~B}$ ). Concrete muscle pyruvate kinase activity for the control group is equal to $679.80 \pm 73.90 \mathrm{nmol} / \mathrm{mg} / \mathrm{min}$, while for the group of rats received $5.0 \mathrm{~g}$ of ethanol per $\mathrm{kg}$ of body 
weight it was equal to $502.10 \pm 59.43 \mathrm{nmol} / \mathrm{mg} / \mathrm{min}(\mathrm{P}$ value for the difference between them is equal to 0.0032 ).
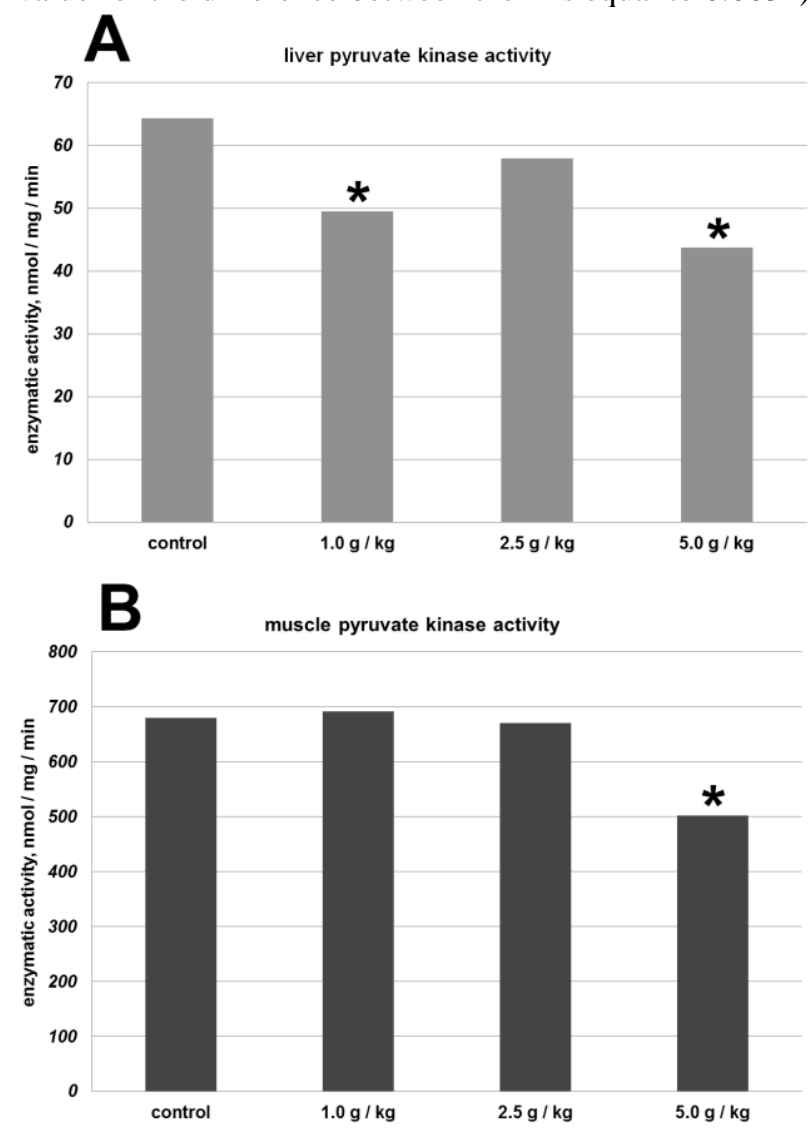

Figure 1. Activities of liver (A) and muscle (B) rat pyruvate kinases in the experiment on the acute alcohol intoxication modeling. Significant differences with control group $(\mathrm{P}<0.05)$ are shown by asterisks.

\subsection{Chronic Alcohol Intoxication}

As one can see in Figure $2 \mathrm{~A}$, after two weeks of regular ethanol intake liver pyruvate kinase activity did not decrease, but, instead of that, it increased to significantly $(\mathrm{P}=0.0327)$ higher level $(82.40 \pm 4.06 \mathrm{nmol} / \mathrm{mg} / \mathrm{min})$ than that in the control group $(75.35 \pm 4.19 \mathrm{nmol} / \mathrm{mg} / \mathrm{min})$. After four weeks of regular ethanol intake enzymatic activity of liver pyruvate kinase was approximately the same $(72.80 \pm 5.67 \mathrm{nmol} / \mathrm{mg} / \mathrm{min})$ as in the control group $(\mathrm{P}=0.4919)$.

Muscle pyruvate kinase activity significantly decreased after two weeks of regular ethanol intake (from $732.70 \pm 24.16 \mathrm{nmol} / \mathrm{mg} / \mathrm{min}$ to $694.70 \pm 21.05 \mathrm{nmol} / \mathrm{mg} / \mathrm{min}$; $\mathrm{P}=0.0345)$. After four weeks of chronic alcohol intoxication muscle pyruvate kinase activity $(683.10 \pm 16.93 \mathrm{nmol} / \mathrm{mg} / \mathrm{min})$ was approximately the same as after two weeks, while it was significantly lower than in the control group $(\mathrm{P}=0.0043)$.

\subsection{Abstinence Syndrome Model}

The third in vivo experiment has been performed with the aim to estimate how long it takes to restore pyruvate kinase activity after the period of regular ethanol intake. As one can see in Figure $3 \mathrm{~A}$, liver pyruvate kinase activity has not been decreased after the five days of $5.0 \mathrm{~g}$ per $\mathrm{kg}$ ethanol intake (twice a day). The concrete liver pyruvate kinase activity in the control group was equal to $84.30 \pm 10.25 \mathrm{nmol} / \mathrm{mg} / \mathrm{min}$, while in the group of rats decapitated after three hours since the last alcohol intake that activity $(83.60 \pm 8.40 \quad \mathrm{nmol} / \mathrm{mg} / \mathrm{min})$ was approximately the same $(\mathrm{P}=0.9193)$. These results are in consistence with the results of chronic alcohol intoxication experiments: liver pyruvate kinase activity is not decreased due to regular ethanol intake.
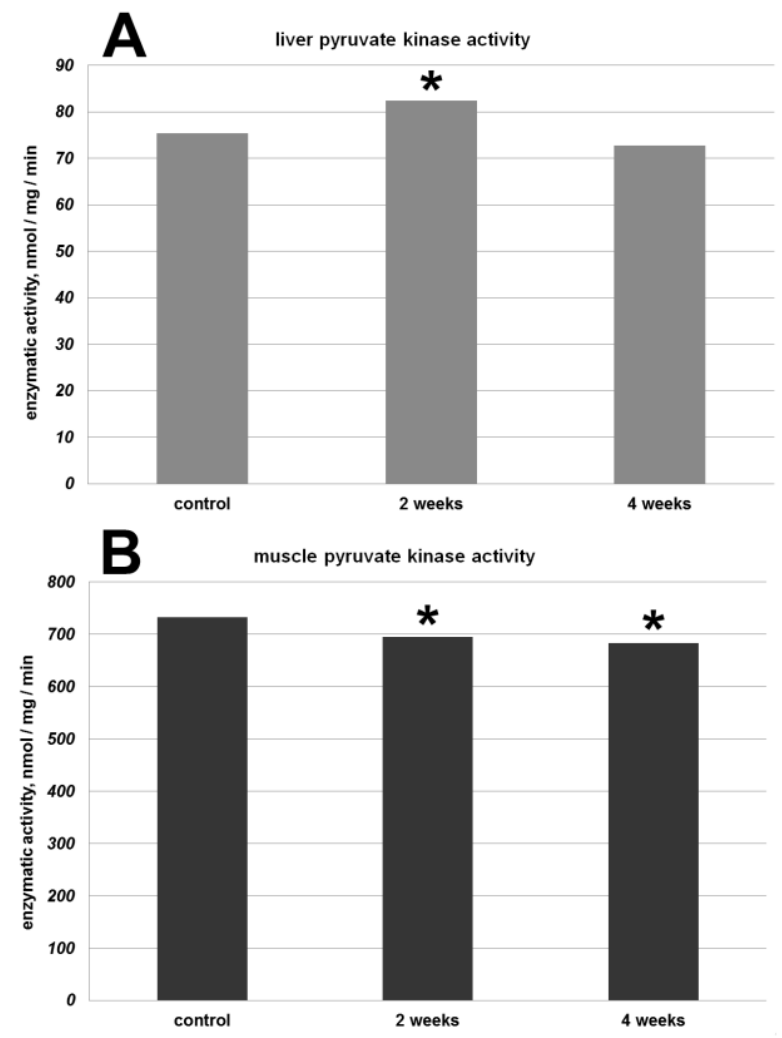

Figure 2. Activities of liver (A) and muscle (B) rat pyruvate kinases in the experiment on the chronic alcohol intoxication modeling. Significant differences with control group $(\mathrm{P}<0.05)$ are shown by asterisks.

The lowest level of muscle pyruvate kinase activity in Figure $3 \mathrm{~B}$ is characteristic to the group of rats decapitated after three hours since the last ethanol intake $(587.57 \pm 22.37 \mathrm{nmol} / \mathrm{mg} / \mathrm{min})$. That level of enzymatic activity was significantly lower $\left(\mathrm{P}=3.15 \cdot 10^{-6}\right)$ than in the control group $(718.11 \pm 12.95 \mathrm{nmol} / \mathrm{mg} / \mathrm{min})$. In groups of rats decapitated in later periods after the last ethanol intake muscle pyruvate activity was higher than that in the group of rats decapitated after three hours, while it was still lower than in the control group (see Figure $3 \mathrm{~B}$ ). There was no significant difference in muscle pyruvate kinase activity between control group and the group of rats decapitated after 3 days (72 hours) since the last ethanol intake $(\mathrm{P}=0.1451)$.

Taken together, results of three in vivo experiments show that muscle pyruvate kinase is inhibited by high dose of alcohol after a single intake as well as during and after the chronic alcohol intoxication, while liver pyruvate kinase is inhibited only in case of acute ethanol intoxication by low and high (but not average) doses of ethanol.

\subsection{Docking of Ethanol to Human and Rat Muscle Pyruvate Kinases}

To suggest the putative molecular mechanism of the direct inhibition of muscle pyruvate kinase by ethanol we performed in silico docking experiments. There is no 
available 3D structure of the rat muscle pyruvate kinase in PDB data base. That is why we performed docking with human homologous protein. Then we modeled 3D structure of the rat enzyme using PDB file for human muscle pyruvate kinase as a template. According to the results of the Docking Server [1] (see Figure 4), ethanol can interact with two amino acid residues (Asn69 and His463) of the human muscle pyruvate kinase at a frequency equal to $90 \%$. Estimated free energy of the binding is equal to $-2.12 \mathrm{kcal} / \mathrm{mol}$. At a frequency equal to $10 \%$ ethanol can interact with His463 residue only by the way of hydrogen bond formation and polar interaction (free energy of the binding is equal to $-2.10 \mathrm{kcal} / \mathrm{mol}$ ). Interacting residues (Asn69 and His463) are situated near each other in the 3D structure of human muscle pyruvate kinase. Here we should state that both Asn69 and His463 (see Figure 4) form allosteric binding site for proline and alanine along with Arg42, Asn43, Arg105, Tyr465, Ile468, Phe469 and Pro470 [11,30]. As one can see in Figure 4 A and Figure 4 B, Docking Server included in the area for potential binding sites search the whole beta-bundle of pyruvate kinase and some parts of the protein situated around the beta-bundle. Putative site for ethanol binding is situated under the beta-bundle of pyruvate kinase, as well as the known allosteric site for proline and alanine binding [11,30].

Results of the docking of ethanol to the 3D model of rat muscle pyruvate kinase obtained with the help of Swiss Model server are analogous to those of the docking to human muscle pyruvate kinase (see Figure 5). There are two interacting residues (Asn70 and His464), which are homologous to those in human muscle pyruvate kinase (see Figure 5). Position of ethanol in the putative binding site is quite similar for rat and human muscle pyruvate kinases (see Figure 4 and Figure 5). At a frequency of $70 \%$ ethanol can interact with His464 by the way of polar interactions with estimated free energy of the binding equal to $-2.06 \mathrm{kcal} / \mathrm{mol}$. At a frequency of $30 \%$ ethanol can interact with both Asn70 and His464 with estimated free energy of the binding equal to $-2.03 \mathrm{kcal} / \mathrm{mol}$.

It is likely that ethanol may inhibit activity of muscle pyruvate kinase by the way of binding to the allosteric site which is known to be involved in interaction with several relatively small molecules, such as alanine, proline and phenylalanine $[11,30]$.

\subsection{Docking of Alanine to Human and Rat Muscle Pyruvate Kinases}

According to the results of the Docking Server, alanine can interact with five amino acid residues (Asn69 and His463, as well as Asn43, Tyr465 and Ile468) of the human muscle pyruvate kinase at a frequency equal to $10 \%$. Estimated free energy of the binding is equal to $3.94 \mathrm{kcal} / \mathrm{mol}$. Hydrogen bonds with alanine are formed by His463, Asn43, Tyr465 and Ile468. Asn69 and His463 participate in polar interactions with the allosteric inhibitor. So, Docking Server recognized five from nine residues of the described allosteric site $[11,30]$. Interestingly, alanine was placed to the substrate-binding site (upon the beta-bundle and not under it) at a frequency of $90 \%$ with higher estimated free energy of binding equal to $-4.88 \mathrm{kcal} / \mathrm{mol}$.

Results of the alanine docking to the modeled rat muscle pyruvate kinase are similar to those described above. This known allosteric inhibitor can be docked to its allosteric site at a frequency of $10 \%$ with estimated free energy of binding equal to $-4.10 \mathrm{kcal} / \mathrm{mol}$. Interacting amino acid residues are: Asn70, His464, Asn44, Tyr466 and Ile469. Hydrogen bonds with alanine are formed by His463, Asn43, Tyr465 and Ile468. Asn70 participates in polar interactions with alanine.
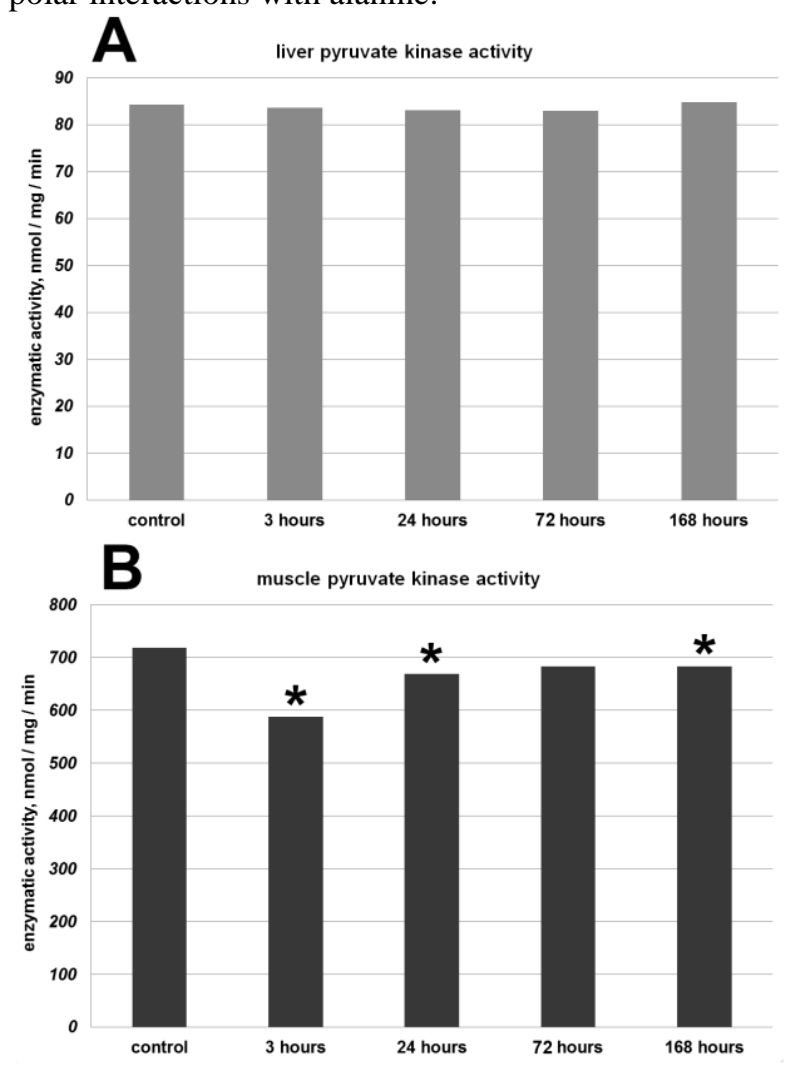

Figure 3. Activities of liver (A) and muscle (B) rat pyruvate kinases in the experiment on the alcohol abstinence syndrome modeling. Significant differences with control group $(\mathrm{P}<0.05)$ are shown by asterisks.

\subsection{Docking of Ethanol to Human and Rat Liver Pyruvate Kinases}

There are five amino acid residues which are involved in ethanol binding by human liver pyruvate kinase: Pro320, Asp354, Ser439, Arg442 and Cys463. As one can see in Figure $6 \mathrm{~A}$ and Figure $6 \mathrm{~B}$, those residues are situated in the area homologous to the muscle pyruvate kinase allosteric site. Moreover, Cys463 residue of human liver pyruvate kinase is homologous to the Tyr465 residue of human muscle pyruvate kinase. Estimated free energy of the binding is equal to $-2.27 \mathrm{kcal} / \mathrm{mol}$. According to the results of the Docking Server, Pro320 and Cys463 are able to form hydrophobic contacts with $\mathrm{CH} 3$ - group of ethanol (see Figure 6 B). Asp354, Ser439 and Arg442 are able to participate in polar interactions with -OH group of ethanol (see Figure 6 B). Moreover, hydrogen from Ser439 -OH group is able to form hydrogen bond with oxygen from ethanol -OH group.

3D structure of the rat liver pyruvate kinase has been modeled on the basis of human liver pyruvate kinase. Estimated free energy of the ethanol binding to that modeled enzyme is equal to $-2.27 \mathrm{kcal} / \mathrm{mol}$. Five amino acid residues participated in ethanol binding at a frequency of 90\% are: Pro335, Asp369, Ser454, Arg457 
and Ser478 (see Figure 7). Four of those residues are conserved in human and rat liver pyruvate kinases. They may participate in the same types of interactions with ethanol in both human and rat enzymes. Serine occupies the place of cysteine in the rat liver pyruvate kinase. Serine cannot take part in hydrophobic interactions with ethanol. However, Ser478 is situated close to the ligand in the modeled structure and its interaction with $\mathrm{CH}_{3}$ - group of ethanol is listed among "other" interactions.
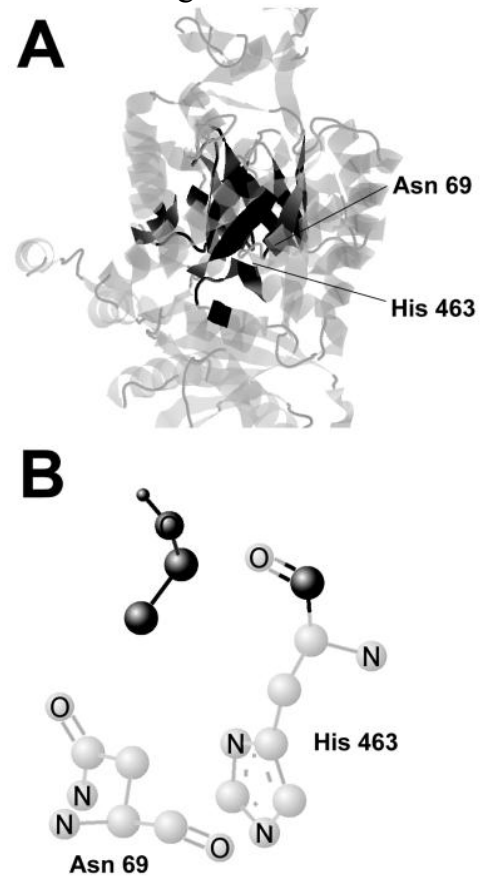

Figure 4. Results of the ethanol docking to human muscle pyruvate kinase (1ZJH). Automatically chosen area for binding site search is shown in black (A); interacting amino acid residues are labeled (B).

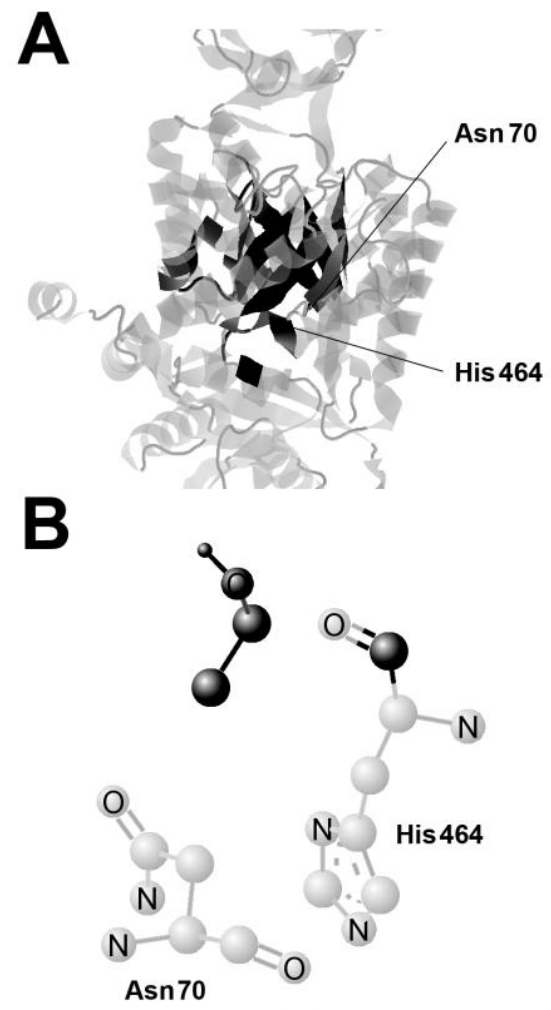

Figure 5. Results of the ethanol docking to rat muscle pyruvate kinase (modeled on basis of $1 \mathrm{ZJH}$ ). Automatically chosen area for binding site search is shown in black (A); interacting amino acid residues are labeled (B).

At a frequency of $10 \%$ ethanol can interact with six amino acid residues from the same area of the rat liver pyruvate kinase. In this version of docking Ser478 (which should be one of the residues forming allosteric site for proline and alanine binding) is able to form hydrogen bond with ethanol; Gln451, Ser454 and Ser478 are involved in polar interactions with it; Pro335, Asp369 and Arg457 are listed among amino acids participating in "other" interactions. Estimated free energy of binding is equal to $-2.22 \mathrm{kcal} / \mathrm{mol}$.

Different amino acid residues have been predicted to participate in ethanol binding to muscle and liver pyruvate kinases. On the other hand, areas of ethanol binding are similar for muscle and liver enzymes. Moreover, two residues from known allosteric site $[11,30]$ are included in putative ethanol binding site for muscle pyruvate kinase and a single residue from the same allosteric site is included in putative ethanol binding site for liver pyruvate kinase. In our opinion, inhibition of pyruvate kinases activity by very high doses of ethanol $(500 \mathrm{mM})$ observed in vitro (see below) may be explained, at least partially, by its binding to the allosteric site situated under the betabundle of those enzymes.
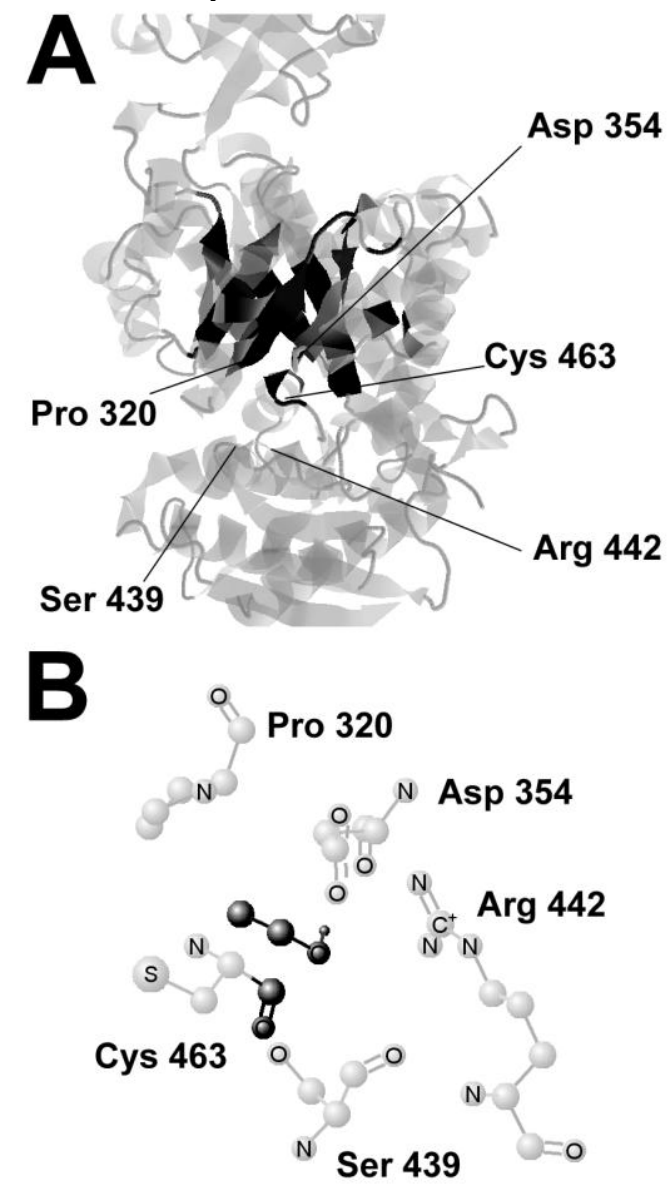

Figure 6. Results of the ethanol docking to human liver pyruvate kinase (2VGB). Automatically chosen area for binding site search is shown in black (A); interacting amino acid residues are labeled (B).

\subsection{Docking of Alanine to Human and Rat Liver Pyruvate Kinases}


There are five amino acid residues which are involved in alanine binding by human liver pyruvate kinase: Asn315, Pro320, Asp354, Ser439 and Arg442. Asn315, Asp344 and Arg442 were shown to participate in polar interactions with the ligand. Estimated free energy of binding (at a frequency of $10 \%$ ) is equal to $-4.84 \mathrm{kcal} / \mathrm{mol}$.

Estimated free energy of the alanine binding to the modeled rat liver enzyme is equal to $-4.82 \mathrm{kcal} / \mathrm{mol}$. Five amino acid residues which participate in alanine binding at a frequency of 30\% are: Asn330, Pro335, Asp369, Ser454 and Arg457. Hydrogen bond may be formed by Arg457; Asn330, Asp369 and Arg457 participate in polar interactions; Pro335 is listed in the column with "other" interactions only.

At a frequency of $70 \%$ alanine can interact with seven amino acid residues from the same area of the rat liver pyruvate kinase. In this version of docking Ser478 is able to form hydrogen bond with alanine along with Gln474 and Val475. Ser478 residue is also involved in polar interactions with alanine. Hydrophobic interactions are formed with Val475 and Leu477. Pro335, Lys278 and Gln451 are listed among amino acids participating in "other" interactions only. Estimated free energy of binding is equal to $-4.62 \mathrm{kcal} / \mathrm{mol}$.

\subsection{Inhibitory Effect of Ethanol on Pyruvate Kinases Activity}

Both pyruvate kinases are inhibited by very high concentration of ethanol in vitro (see Figure 8).
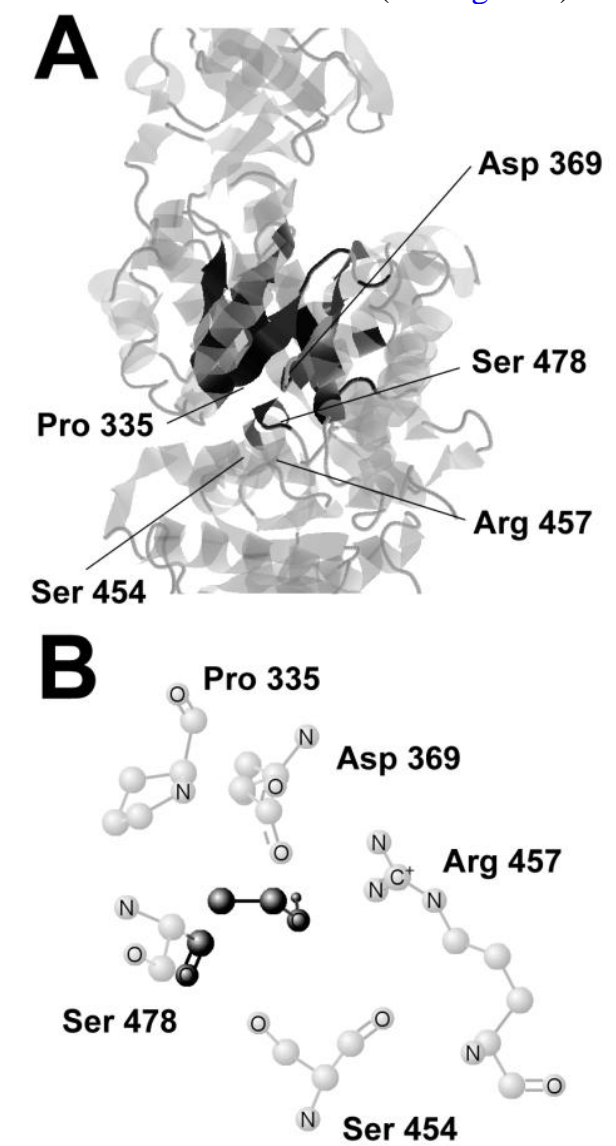

Figure 7. Results of the ethanol docking to rat liver pyruvate kinase (modeled on basis of 2VGB). Automatically chosen area for binding site search is shown in black (A); interacting amino acid residues are labeled (B).
Enzymatic activity of the liver pyruvate kinase became 1.6 times lower (activity in the control group is equal to $69.29 \pm 5.66 \mathrm{nmol} / \mathrm{mg} / \mathrm{min}$; activity in the presence of $500 \mathrm{mM}$ ethanol is equal to $43.11 \pm 4.99 \mathrm{nmol} / \mathrm{mg} / \mathrm{min}$; Pvalue for the difference between them is equal to $5.12 \cdot 10^{-5}$ ) in the presence of ethanol in that concentration (see Figure 8 A).

As one can see in Figure 8 B, enzymatic activity of the muscle pyruvate kinase became 1.4 times lower in the presence of $500 \mathrm{mM}$ ethanol (activity in the control group is equal to $701.70 \pm 20.24 \mathrm{nmol} / \mathrm{mg} / \mathrm{min}$; activity in the presence of $500 \mathrm{mM}$ ethanol is equal to $502.00 \pm 31.07 \mathrm{nmol} / \mathrm{mg} / \mathrm{min}$; P-value for the difference between them is equal to $3.27 \cdot 10^{-6}$ ).

These results gave us an evidence of the fact that ethanol is able to inhibit activity of both pyruvate kinases taken in concentration which can never be reached in a living cell $(500 \mathrm{mM})$.

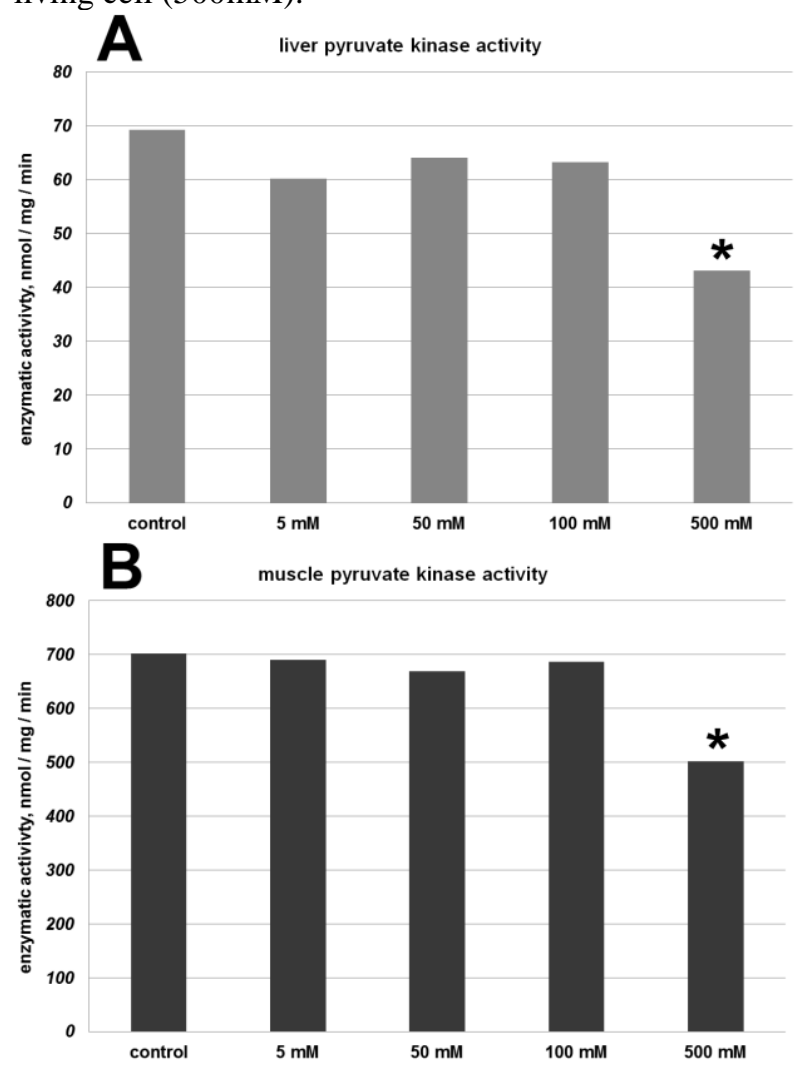

Figure 8. Activities of liver (A) and muscle (B) rat pyruvate kinases after addition of ethanol to supernatants. Significant differences with control group $(\mathrm{P}<0.05)$ are shown by asterisks.

\subsection{Lactate Dehydrogenase Activity is not Inhibited by Ethanol}

Lactate dehydrogenase activity in the control human plasma was equal to $132.53 \pm 3.42 \mathrm{U} / \mathrm{L}$. Enzymatic activity has not been changed significantly by $50 \mathrm{mM}$ $(133.95 \pm 11.17 \mathrm{U} / \mathrm{L}), 100 \mathrm{mM}(141.08 \pm 9.26 \mathrm{U} / \mathrm{L})$ and 500 $\mathrm{mM}(136.80 \pm 8.14 \mathrm{U} / \mathrm{L})$ of ethanol relatively to that in the absence of ethanol (P-values are equal to $0.8681 ; 0.1650$ and 0.4244 , respectively).

These results showed that ethanol does not inhibit lactate dehydrogenase activity. So, the results described in section 3.8 are valid. Inhibitory effect of the $500 \mathrm{mM}$ ethanol on pyruvate kinase activity is due to the binding of 
ethanol by pyruvate kinase and not due to the binding of ethanol by lactate dehydrogenase from the coupled assay.

\subsection{Glucose Blood Levels in Rats during Acute and Chronic Alcohol Intoxication}

In rats received $1.0 \mathrm{~g}$ per $\mathrm{kg}$ of ethanol in the experiment on acute alcohol intoxication modeling an average glucose blood level was approximately the same as that in the control group $(5.39 \pm 0.52$ vs. $5.23 \pm 0.58 \mathrm{mmol} / \mathrm{L} ; \mathrm{P}=$ 0.6929). In rats received higher doses of ethanol average glucose blood levels were significantly higher (P-values are equal to 0.0002 and 0.0001 , respectively) than in control group: $2.5 \mathrm{~g} / \mathrm{kg}$ of ethanol $-7.29 \pm 0.46 \mathrm{mmol} / \mathrm{L}$ of glucose; $5.0 \mathrm{~g} / \mathrm{kg}$ of ethanol $-7.36 \pm 0.34 \mathrm{mmol} / \mathrm{L}$ of glucose. These data are in consistence with results of other studies $[5,20,21]$. The increase of glucose blood level should stimulate liver pyruvate kinase expression [6]. In case of $2.5 \mathrm{~g} / \mathrm{kg}$ of ethanol intake the indirect inhibition by ethanol seemed to be compensated by the indirect activation associated with increase of glucose blood level. In case of $5.0 \mathrm{~g} / \mathrm{kg}$ of ethanol intake indirect mechanism (or mechanisms) of liver pyruvate kinase activation failed to compensate that inhibition.

The growth of liver pyruvate kinase activity in rats after two weeks of regular alcohol intake can be explained in a similar way. Average glucose blood level in the abovementioned group of rats $(5.86 \pm 1.05 \mathrm{mmol} / \mathrm{L})$ was significantly higher $(\mathrm{P}=0.042)$ than that in the control group $(4.41 \pm 0.37 \mathrm{mmol} / \mathrm{L})$. In the group of rats regularly received ethanol for four weeks average glucose level $(5.03 \pm 0.17 \mathrm{mmol} / \mathrm{L})$ was also significantly higher $(\mathrm{P}=$ $0.0100)$ than in the control group. So, one of the probable mechanisms of indirect liver pyruvate kinase activation during the period of alcohol consumption is associated with the increase of glucose blood level.

\section{Discussion}

It is widely accepted that activity of both liver and muscle pyruvate kinases is regulated by their substrate (PEP) and by several allosteric regulators including their products (ATP and pyruvate) and other molecules (fructose 1,6-bisphosphate, acetyl-CoA, alanine, phenylalanine and proline) [2,9,11]. Activity of liver pyruvate kinase, unlike that of muscle pyruvate kinase, is also regulated in indirect manner by such hormones as insulin (it activates liver pyruvate kinase promoting its dephosphorylation), epinephrine and glucagon (they deactivate liver pyruvate kinase promoting its phosphorylation) [2]. Moreover, glucose itself is able to promote expression of the gene coding for liver pyruvate kinase [6]. So, elevated glucose blood level is a signal leading to the increase of liver pyruvate kinase expression.

According to the data represented in Figure 9, the divergence between the gene coding for liver pyruvate kinase and the gene coding for muscle pyruvate kinase happened sometime between 713.2 and 535.7 million years ago. As one can see in Figure 9, pyruvate kinase from lancelet is a common outgroup for branches leading to muscle and liver enzymes of primates and rodents. The time of the divergence between lancelets and the predecessor of vertebrates is 713.2 Mya [18]. The gene coding for lancelet pyruvate kinase has been reconstructed by us from two different nucleotide sequences one of which is partial. That is why we used yet another outgroup (full length pyruvate kinase from oyster) in the dendrogram from Figure 9.

Predicted protein from the lamprey genome annotated as liver and red blood cells pyruvate kinase in Ensembl data base behaves like muscle pyruvate kinase in Figure 9. In our opinion, there was a mistake in gene annotation during automatic analysis of lamprey genome. Anyway we should state that lamprey already possesses one of the organ-specific pyruvate kinases. The second one will probably be discovered soon. It means that the divergence between liver and muscle pyruvate kinases happened before the divergence of lampreys and other vertebrates (before 535.7 Mya) [18].

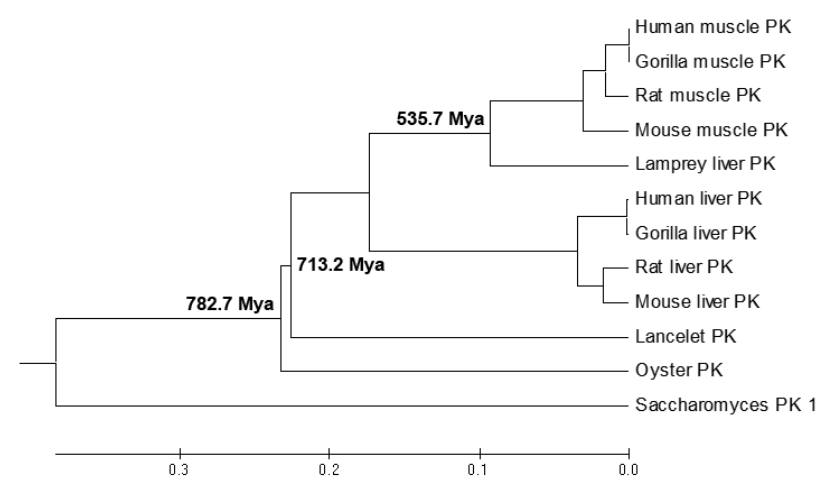

Figure 9. UPGMA phylogenetic tree built on basis of JTT amino acid distances between sequences of pyruvate kinases aligned by PAM method.

Divergence of two organ-specific pyruvate kinases happened in times when systems of organs characteristic to vertebrates have been formed in their common predecessor. Since those times liver pyruvate kinase became a subject for indirect (or central) regulation, unlike muscle pyruvate kinase. Architecture of the allosteric site for alanine binding has also been changed during this period of time. According to the in silico docking, equilibrium constant for alanine binding is $3-4$ times higher for liver pyruvate kinases than for their muscle homologues (see Table 1).

Results described in this paper showed that high doses of ethanol indirectly inhibit activity of both pyruvate kinases in the experiment on acute alcohol intoxication. Certain indirect mechanism (or mechanisms) is responsible of the increase of liver pyruvate activity during the period of chronic alcohol intake. Direct inhibition of muscle and liver pyruvate kinases activity by ethanol may also take place, but in vitro and not in vivo. In Table 1 we placed equilibrium constants for alanine (a known allosteric inhibitor) and ethanol binding by the same site of liver and muscle pyruvate kinases. As one can see, those constants for alanine binding are $\sim 20-30$ times higher than for ethanol binding in case of muscle pyruvate kinases. For liver pyruvate kinases equilibrium constants of alanine binding are more than 60 times higher than those for ethanol binding. These results of in silico docking are in consistence with the results of in vitro experiments: only the highest concentration of ethanol which is not characteristic for living cells $(500 \mathrm{mM})$ may inhibit pyruvate kinase activity.

One of the possible pathways of indirect liver pyruvate kinas activity regulation is a pathway linked to glucose 
blood level [6]. According to our results (see section 3.10) glucose blood level was elevated during chronic alcohol intoxication as well as after the intake of average or high bolus dose of ethanol.

It was shown that such amino acids as tryptophan, phenylalanine and alanine are able to inhibit pyruvate kinase activity [8]. Those amino acids act at the same allosteric site of the enzyme. According to the results of in silico docking ethanol is also able to act on that allosteric site. Tryptophan and phenylalanine have much stronger inhibitory effects on pyruvate kinase activity than alanine [8]. That is why alanine prevents inhibitory effects of tryptophan and phenylalanine [8]. However, alanine itself is also an allosteric inhibitor of pyruvate kinase [10].

Table 1. Equilibrium constants for alanine and ethanol binding calculated from estimated free energies of binding

\begin{tabular}{|c|c|c|c|c|}
\hline Ligand & $\begin{array}{c}\text { Human } \\
\text { liver } \\
\text { pyruvate } \\
\text { kinase }\end{array}$ & $\begin{array}{c}\text { Rat liver } \\
\text { pyruvate } \\
\text { kinase }\end{array}$ & $\begin{array}{c}\text { Human } \\
\text { muscle } \\
\text { pyruvate } \\
\text { kinase }\end{array}$ & $\begin{array}{c}\text { Rat } \\
\text { muscle } \\
\text { pyruvate } \\
\text { kinase }\end{array}$ \\
\hline Alanine & 2554.67 & 2473.18 & 593.94 & 769.80 \\
\hline Ethanol & 39.63 & 39.63 & 31.08 & 28.20 \\
\hline $\begin{array}{c}\text { Ratio } \\
\text { between } \\
\text { alanine and } \\
\text { ethanol } \\
\text { equilibrium } \\
\text { binding } \\
\text { constants }\end{array}$ & 64.46 & 62.41 & 19.11 & 27.30 \\
\hline
\end{tabular}

According to the data from several sources [3,19,25], chronic alcohol consumption leads to the decrease of alanine blood level. The higher is the blood level of ethanol, the lower is the blood level of alanine [3]. One may suggest that this decrease of alanine blood level should result in the inhibition of pyruvate kinase activity by tryptophan and phenylalanine. However, levels of those aromatic amino acids also decrease in the period of chronic alcohol intoxication [19]. Equilibrium constant for ethanol binding is more than 60 times lower for ethanol than for alanine. As a result, activity of liver pyruvate kinase may increase in rats after two weeks of regular alcohol intake due to the decrease of the level of amino acids (tryptophan, phenylalanine and alanine) which are stronger allosteric inhibitors of that enzyme than ethanol.

\section{Conclusion}

Both muscle and liver rat pyruvate kinases are inhibited by high bolus doses of ethanol, while liver pyruvate kinase may be activated indirectly during the period of chronic alcohol consumption. Direct inhibition of pyruvate kinases activity may be caused by ethanol binding to their allosteric site, which is known to be involved in inhibition of muscle pyruvate kinase activity by proline, phenylalanine and alanine. However, that direct inhibition by $500 \mathrm{mM}$ of ethanol is impossible in living cells. Indirect activation of liver pyruvate kinase activity may be associated with the increase of glucose blood level after alcohol intake, as well as with the decrease of alanine concentration in liver.

\section{Statement of Competing Interests}

The authors have no competing interests.

\section{References}

[1] Bikadi, Z., Hazai, E. "Application of the PM6 semi-empirical method to modeling proteins enhances docking accuracy of AutoDock". J. Cheminf. 1. 15. 2009

[2] Blair, J.B., Sattsangi, S., Hartw, R. "Regulation of pyruvate kinase in cultured rat hepatocytes: influence of glucose, ethanol, glucagon, and dexamethasone". J. Biol. Chem. 261. 2425-2433. 1986.

[3] Dahchour, A., Hoffman, A., Deitrich, R., De Witte, P. "Effects of ethanol on extracellular amino acid levels in high- and low-alcohol sensitive rats: a microdialysis study". Alcohol and Alcoholism. 35. 548-553. 2000.

[4] Dudka, J., Burdan, F., Korobowicz, A., Klepacz, R. and Korobowicz, E. "Human skeletal muscle lactate dehydrogenase activity in the presence of some alcohol dehydrogenase inhibitors". Pharm. Toxicol. 95, 38-42. 2004.

[5] Duruibe, V., Tejwani, C.A. "The effect of ethanol on the activities of the key gluconeogenic and glycolytic enzymes of rat liver". Mol. Pharmacol. 20. 621-630. 1981.

[6] Eckert, D.T., Zhang, P., Collier, J.J., O’Doherty, R.M., Scott, D.K. "Detailed molecular analysis of the induction of the L-PK gene by glucose”. Biochem. Biophys. Res. Commun. 372, 131-136. 2008.

[7] Faingold, C.L. "The Majchrowicz binge alcohol protocol: an intubation technique to study alcohol dependence in rats". Curr. Protoc. Neurosci. Ch. 9, Unit 9.28. 2008.

[8] Feksa, L.R., Cornelio, A.R., Vargas, C.R., de Souza Wyse, A.T., Dutra-Filho, C.S., Wajner, M., Wannmacher, C.M. "Alanine prevents the inhibition of pyruvate kinase activity caused by tryptophan in cerebral cortex of rats". Metab. Brain Dis. 18, 129137. 2003.

[9] Fenton, A.W., Alontaga, A.Y. "The impact of ions on allosteric functions in human liver pyruvate kinase". Methods Enzymol. 466 , 83-107. 2009.

[10] Fenton, A.W., Hutchinson, M. "The $\mathrm{pH}$ dependence of the allosteric response of human liver pyruvate kinase to fructose-1,6bisphosphate, ATP, and alanine". Arch. Biochem. Biophys. 484, 16-23. 2009.

[11] Fenton, A.W., Johnson, T.A., Holyoak, T. "The pyruvate kinase model system, a cautionary tale for the use of osmolyte perturbations to support conformational equilibria in allostery". Protein Science 19, 1796-1800. 2010.

[12] Flicek, P., Amode, M.R., Barrell, D., Beal, K., Brent, S., Carvalho-Silva, D., Clapham, P., Coates, G., Fairley, S., Fitzgerald, S., Gil, L., Gordon, L., Hendrix, M., Hourlier, T., Johnson, N., Kähäri, A., Keefe, D., Keenan, S., Kinsella, R., Komorowska, M., Koscielny, G., Kulesha, E., Larsson, P., Longden, I., McLaren, W., Muffato, M., Overduin, B., Pignatelli, M., Pritchard, B., Riat, H.S., Ritchie, G.R.S., Ruffier, M., Schuster, M., Sobral, D., Tang, Y.A., Taylor, K., Trevanion, S., Vandrovcova, J., White, S., Wilson, M., Wilder, S.P., Aken, B.L., Birney, E., Cunningham, F., Dunham, I., Durbin, R., FernándezSuárez, X.M., Harrow, J., Herrero, J., Hubbard, T.J.P., Parker, A., Proctor, G., Spudich, G., Vogel, J., Yates, A., Zadissa, A., Searle, S.M.J. "Ensembl 2012". Nucl. Acids Res. 40. D84-D90. 2012.

[13] Hassan, S., Duong, B., Kim, K.S., Miles, M.F. "Pharmacogenomic analysis of mechanisms mediating ethanol regulation of dopamine $\beta$-hydroxylase". J. Biol. Chem. 278. 38860-38869. 2003.

[14] Huey, R., Morris, G.M., Olson, A.J., Goodsell, D.S. "A semiempirical free energy force field with charge-based desolvation". J. Comput. Chem. 28. 1145-1152. 2007.

[15] Khrustalev, V.V., Arjomandzadegan, M., Barkovsky E.V., Titov L.P. "Low rates of synonymous mutations in sequences of Mycobacterium tuberculosis GyrA and KatG genes". Tuberculosis 92. 333-344. 2012.

[16] Khrustalev, V.V., Barkovsky E.V. "Unusual nucleotide content of Rubella virus genome as a consequence of biased RNA-editing: comparison with Alphaviruses". Int. J. Bioinf. Res. Appl. 7. 82100. 2011.

[17] Kiefer, F., Arnold, K., Künzli, M., Bordoli, L., Schwede, T. "The SWISS-MODEL repository and associated resources". Nucl. Acids Res. 37. D387-D392. 2009.

[18] Kumar, S., Hedges, S.B. "TimeTree2: species divergence times on the iPhone". Bioinf. 27. 2023-2024. 2011.

[19] Ledig, M., M'Paria, J.R., Mandel, P. "Free amino acids in the brain of ethanol treated rats". Subst. Alcohol Actions Misuse 3, 25 30. 1982. 
[20] Leggio, L., Ray, L.A., Kenna, G.A., Swift, R.M. "Blood glucose level, alcohol heavy drinking and alcohol craving during treatment for alcohol dependence: results from the combined pharmacotherapies and behavioral interventions for alcohol dependence (COMBINE) study". Alcohol Clin. Exp. Res. 33. 1539-1544. 2009.

[21] Leiber, C.S. "Ethanol metabolism, cirrhosis and alcoholism". Clin. Chim. Acta 257. 59-84. 1997.

[22] Li, J., Bardag-Gorce, F., Oliva, J., Dedes, J., French, B.A., French, S.W. "Gene expression modifications in the liver caused by binge drinking and S-adenosylmethionine feeding. The role of epigenetic changes." Genes Nutr. 5. 169-179. 2010.

[23] Meera, P., Olsen, R.W., Otis, T.S., Wallner, M. "Alcohol- and alcohol antagonist-sensitive human $\mathrm{GABA}_{\mathrm{A}}$ receptors: tracking $\delta$ subunit incorporation into functional receptors". Mol. Pharmacol. 78, 918-924. 2010

[24] Nei, M., Kumar, S. "Molecular evolution and phylogenetics". Oxford University Press, New York. 2000.

[25] Nicholas, P.C., Kim, D., Crews, F.T., Macdonald, J.M. "1H NMRbased metabolomic analysis of liver, serum, and brain following ethanol administration in rats." Chem. Res. Toxicol. 21. 408-420. 2008.

[26] Plagnes-Juan, E., Lansard, M., Seiliez, I., Médale, F., Corraze, G., Kaushik, S., Panserat, S., Skiba-Cassy, S. "Insulin regulates the expression of several metabolism-related genes in the liver and primary hepatocytes of rainbow trout (Oncorhynchus mykiss)". $J$. Experim. Biol. 211. 2510-2518. 2008.
[27] Ren, H., Salous, A.K., Paul, J.M., Lamb, K.A., Dwyer, D.S., Peoples, R.W. "Functional interactions of alcohol-sensitive sites in the N-methyl-D-aspartate receptor M3 and M4 domains". J. Biol. Chem. 283. 8250-8257. 2008.

[28] Tamura, K., Peterson, D., Peterson, N., Stecher, G., Nei, M., Kumar, S. MEGA5: "Molecular Evolutionary Genetics Analysis using Maximum Likelihood, Evolutionary Distance, and Maximum Parsimony Methods". Mol. Biol. Evol. 28. 2731-2739. 2011.

[29] Valentini, G., Chiarelli, L.R., Fortin, R., Dolzan, M., Galizzi, A., Abraham, D.J., Wang, C., Bianchi, P., Zanella, A., Mattevi, A. "Structure and function of human erythrocyte pyruvate kinase: molecular basis of nonspherocytic hemolytic anemia". J. Biol. Chem. 277. 23807-23814. 2002.

[30] Williams, R., Holyoak, T., McDonald, G., Gui, C., Fenton, A.W. "Differentiating a ligand's chemical requirements for allosteric interactions from those for protein binding. Phenylalanine inhibition of pyruvate kinase". Biochemistry 45. 5421-5429. 2006.

[31] Yevenes, G.E., Moraga-Cid, G., Avila, A., Guzman, L., Figueroa, M., Peoples, R.W., Aguayo, L.G. "Molecular requirements for ethanol differential allosteric modulation of glycine receptors based on selective G $\beta \gamma$ modulation". J. Biol. Chem. 285. 3020330213. 2010.

[32] Yu., H.C., Li, S.Y., Cao, M.F., Jiang, X.Y, Feng, L., Zhao, J.J., Gao, L. "Effects of chronic ethanol consumption on levels of adipokines in visceral adipose tissues and sera of rats." Acta Pharmacol. Sin. 31. 461-469. 2010. 